\title{
Role of immune complexes in hypertrophic osteoarthropathy and nonmetastatic polyarthritis
}

\author{
MARK S. AWERBUCH AND PETER M. BROOKS \\ From the Department of Medicine, Repatriation General Hospital, Daw Park, South Australia 5041
}

SUMMARY Three case histories of patients with histologically proved malignant disease and an associated nonmetastatic symmetrical polyarthropathy are analysed. No evidence of a pathogenetic role for immune complexes was found in hypertrophic osteoarthropathy, whereas there is considerable evidence suggesting that the nonmetastatic polyarthritis associated with malignant lymphoma is an immune complex phenomenon.

Hypertrophic osteoarthropathy (HOA) and nonmetastatic polyarthritis are relatively uncommon but well recognised syndromes seen in association with malignant disease. Despite the noninflammatory nature of the synovial fluid in the former, ${ }^{1-3}$ both may present clinically as an inflammatory arthropathy with a similar joint distribution. And where there exists no clinical or radiographic evidence of periosteal change and where clubbing is subtle or absent, these 2 arthropathies may be indistinguishable from one another or from other arthropathies. ${ }^{1245}$ Their pathogenesis is unknown. We have examined 3 patients with histologically proved malignant disease and an associated non-metastatic symmetrical polyarthropathy in an attempt to determine the pathogenesis.

\section{Material and methods}

Circulating and intra-articular immune complexes were detected by the Clq binding assay. ${ }^{6}$ The results were expressed as micrograms of a preparation of heat aggregated human IgG (HAGG) per ml of serum. HAGG was prepared by heating Cohn fraction II gammaglobulin $(20 \mathrm{mg} / \mathrm{ml})$ at $63^{\circ} \mathrm{C}$ for 30 minutes and diluting in normal human serum.

Antinuclear antibody titres were performed by a standard indirect immunofluorescence technique.

Synovial fluid viscosity was judged by the length of 'stringing' of a falling drop of synovial fluid.'

Serum and intra-articular levels of $\mathrm{C} 3$ and $\mathrm{C} 4$ were measured by the automated immunoprecipitation method, Technicon.

Accepted for publication 14 November 1980.

Correspondence to Dr M. S. Awerbuch, Repatriation General Hospital, Daw Park, South Australia 5041.

\section{CASE REPORTS}

Case 1. The patient, a 62-year-old retired butcher, who presented with a chronic unproductive cough, was found to have a nonresectable squamous carcinoma of the lung. When first seen, he had marked clubbing of the fingers and toes but noo evidence of an arthropathy. It was decided to withhold radiotherapy until symptoms appeared. Nine months later he presented with a symmetrical polyarthritis involving the ankles, knees, and wrists. The joints were warm and effusions were present.

Investigations showed the following: Haemoglobin $14.5 \mathrm{~g} / \mathrm{dl}$, leucocytes $7.3 \times 10^{9} / 1$, ESR $41 \mathrm{~mm} /$ hour, IgM rheumatoid factor was not detected (latex test and sheep cell agglutination), and antinuclear factor was weakly positive (dilution 1:40), serum levels of circulating immune complexes (CICs) were normal (less than $40 \mu \mathrm{g} / \mathrm{ml}$ ). Synovial fluid analysis revealed fluid of normal viscosity, leucocytes $0.25 \times 10^{9} / 1$ (mainly lymphocytes), immune complexes $62 \mu \mathrm{g} / \mathrm{ml}$, protein $2.9 \mathrm{~g} / 100 \mathrm{ml}$ $(29 \mathrm{~g} / \mathrm{l})$ and immunochemical levels of complement were normal for this protein concentration (C3 $27 \mathrm{mg} / 100 \mathrm{ml}$ and $\mathrm{C} 44 \mathrm{mg} / 100 \mathrm{ml}$ ) (SI conversion: $\mathrm{g} / \mathrm{l}=\mathrm{mg} / 100 \mathrm{ml} \times 0.01)$. No organisms were cultured and no crystals were found. Radiographs were suggestive of bilateral lung metastases, there were no bone erosions or periosteal changes, and skeletal imaging with technetium-labelled diphosphonate was normal. No malignant cells were found on synovial biopsy, and immunofluorescence was negative. The patient was started on $75 \mathrm{mg}$ of indomethacin a day. When seen at an outpatient clinic 4 weeks later he had less joint pain, although both knees were still warm and small effusions were 
present. Three months later there was no obvious change in the arthropathy, but he complained of pain just proximal to both wrists. Radiographs were normal, but bone scintigraphy showed pericortical linear accumulation of isotope, characteristic of periosteal new bone formation. ${ }^{8}$

Case 2. The patient is a 66-year-old man who presented with a 10-week history of polyarthritis and weight loss. On examination he was found to have severe clubbing of the fingers and toes, thickening and tenderness over the distal ends of the radius and ulna, and symmetrically warm and swollen ankles, knees, wrists, metacarpophalangeal joints and proximal interphalangeal joints of the fingers.

Investigations showed the following: Haemoglobin $12.6 \mathrm{~g} / \mathrm{dl}$, leucocytes $8.6 \times 10^{9} / 1$, ESR $76 \mathrm{~mm} /$ hour. Neither IgM rheumatoid factor nor ANF were detected. CICs in the blood were $500 \mu \mathrm{g} / \mathrm{ml}$ (normal less than $40 \mu \mathrm{g} / \mathrm{ml}$ ), the serum C3 level was $110 \mathrm{mg} / 100 \mathrm{ml}$ (normal range 55-120) and the serum $\mathrm{C} 4$ level $40 \mathrm{mg} / 100 \mathrm{ml}$ (normal 20 50) (SI conversion: $\mathrm{g} / \mathrm{l}=\mathrm{mg} / 100 \mathrm{ml} \times 0.01$ ). Synovial fluid analysis revealed fluid of reduced viscosity, leucocytes $0.75 \times 10^{9} / 1$, immune complexes $80 \mu \mathrm{g} / \mathrm{ml}$, protein $3 \cdot 1 \mathrm{~g} / 100 \mathrm{ml}(31 \mathrm{~g} / \mathrm{l})$, and normal complement levels for this protein concentration (C3 $30 \mathrm{mg} / 100 \mathrm{ml}$ and C4 $5 \mathrm{mg} / 100 \mathrm{ml}$ ). No crystals or malignant cells were seen, and the synovial biopsy showed no metastases or inflammatory cell infiltrate, and immunofluorescence was negative. $X$-rays showed a small opacity in the left lung base and marked subperiosteal new bone formation over the distal ends of the femur, radius, and ulna, but no bone erosions or obvious metastatic deposits were seen. Skeletal imaging showed pericortical linear accumulation of the isotope characteristic of subperiosteal new bone formation, increased isotope uptake in involved joints, and no evidence of metastatic bone disease.

Bronchoscopy was followed by thoracotomy, and a neoplasm removed was found to be an adenocarcinoma. Within 24 hours of the operation joint symptoms had disappeared and swelling had subsided despite persistently high blood levels of CICs. One week postoperatively the patient developed painful swellings in the proximal left radius and distal right femur. These were found on skeletal imaging to be highly suggestive of metastatic deposits, and this was confirmed by open biopsy. When this scan was compared with the preoperative scan, a diminution of the pericortical linear accumulation of the tracer was noted. Repeat $x$-rays revealed no obvious change in the degree of periosteal new bone formation. Despite this metastatic recurrence, neither the arthropathy nor the pain and tenderness at the distal ends of the radii and ulnae recurred, and clubbing is continuing to resolve.

Case 3. The patient, a 62-year-old man, who presented with a pyrexia of unknown origin and diffuse lymphadenopathy was found to have a poorly differentiated lymphocytic lymphoma, stage 3b. Two weeks after diagnosis he developed a widespread symmetrical polyarthritis involving the ankles, wrists, and elbows, a pericardial friction rub, and haematuria.

Investigations showed the following: Haemoglobin $14 \cdot 2 \mathrm{~g} / \mathrm{dl}$, leucocytes $11 \times 10^{9} / 1$, ESR $93 \mathrm{~mm} /$ hour; IgM rheumatoid factor was not detected, the ANF was weakly positive, serum C3 was $95 \mathrm{mg} /$ $100 \mathrm{ml}$ and $\mathrm{C} 438 \mathrm{mg} / 100 \mathrm{ml}$ (SI conversion: $\mathrm{g} / \mathrm{l}=$ $\mathrm{mg} / 100 \mathrm{ml} \times 0.01) \mathrm{CICs}$ in the serum were $400 \mu \mathrm{g} /$ $\mathrm{ml}$. Blood cultures were negative. Synovial fluid analysis revealed reduced viscosity, leucocytes $1 \cdot 5 \times$ $10^{9} / 1$ (90\% polymorphs), protein $4 \mathrm{~g} / 1000 \mathrm{ml}$ $(40 \mathrm{~g} / \mathrm{l})$, and immune complexes of greater than $1500 \mu \mathrm{g} / \mathrm{ml}$; immunochemical levels of complement were undetectable. There was no growth or crystals. Synovial biopsy showed no evidence of lymphomatous infiltration of the synovium. Unfortunately the specimen was misplaced and immunofluorescence was not done. Echocardiography cunfirmed a moderate sized pericardial effusion. Renal biopsy showed a mesangial proliferative glomerulonephritis with areas of acute tubular necrosis. Immunofluorescence showed deposits of C3.

The patient was started on immnuosuppressive therapy (prednisolone, vincristine, and cyclophosphamide). Within 48 hours his arthropathy had clinically disappeared and the pericardial rub was no longer heard. The nephropathy resolved within 72 hours. Repeat serum levels of CICs taken 2 weeks later at a time when the patient was asymptomatic were normal. The patient has remained asymptomatic for 3 months.

\section{Discussion}

Patient 1 had a symmetrical polyarthritis with all the clinical signs of inflammation as well as marked clubbing of the digits. Analysis of the synovial fluid, however, showed it to be noninflammatory. This apparent dissociation between clinical signs and synovial fluid analysis is found in hypertrophic osteoarthropathy. ${ }^{12}$ Initially this patient had no evidence of periosteal new bone formation but later developed characteristic scintigraphic changes. Schumacher has emphasised that typical periostal changes may be absent in HOA of relatively recent onset. $^{2}$

Patient 2 had classical HOA. The dramatic symptomatic improvement of the arthropathy following 
tumour resection is well described ${ }^{12}$ and has recently been documented following chemotherapy. ${ }^{9}$ The failure of recurrence of the arthropathy with extrathoracic metastases has been previously reported. ${ }^{3510}$ Of interest in this patient is that no recurrence occurred despite the high levels of CICs. As in patient 1 , levels of immune complexes in the synovial fluid were not significant, the synovial fluid was noninflammatory in nature, although there was a reduction in viscosity, complement levels were normal. and immunofluorescence was negative. In neither case therefore is there a suggestion of an immunecomplex pathogenesis. Schumacher, ${ }^{2}$ however, found electron-dense vascular deposits in the synovium of patients with HOA not unlike those seen in the renal glomeruli of patients with immune complex nephritis. He speculated that these might consist of tumourderived materials and/or antigen antibody complexes, although levels of CICs were not measured. Although we did not do ultrastructural studies on the synovium, investigations in our 2 patients with HOA did not suggest that the pathogenesis was immune-complex mediated. Recently Vidal et al. ${ }^{11}$ testing HOA synovial tissue with fluoresceinconjugated antisera to immunoglobulins and complement components were also unable to find evidence supporting an antigen-antibody immunedeposit mechanism in the pathogenesis of HOA.

Patient 3 had a nonmetastatic polyarthritis associated with malignant lymphoma. The high levels of CICs in the blood, the even higher levels of immune complexes in the synovial fluid, plus the undetectable complement levels in the synovial fluid, followed by a fall in blood CIC levels to normal once the arthropathy had clinically resolved, are good evidence that in this patient the pathogenesis of the nonmetastatic polyarthritis was immune-complex mediated. In spite of being unable to perform immunofluorescence on the synovium all the other evidence together with the simultaneous presence of an immune-complex nephritis lends further support to this suggestion.

The relative rarity of the conditions reported makes the collection of a large series difficult. The evidence suggests that hypertrophic osteoarthropathy is unlikely to be an immune-complex-mediated condition. In the single patient with nonmetastatic polyarthritis associated with lymphoma the evidence does suggest an immune-complex mediated disease.

\section{References}

1 Calabro J J. Cancer and arthritis. Arthritis Rheum 1967; 10: 553-67.

2 Schumacher H R. Articular manifestations of hypertrophic pulmonary osteoarthropathy in bronchogenic carcinoma. Arthritis Rheum 1976; 19: 629-36.

3 Awerbuch M S. Hypertrophic osteoarthropathy-an important differential diagnosis. Med J Aust 1977; ii: 287-90.

4 Ginsburg J. Hypertrophic pulmonary osteoarthropathy. Postgrad Med J 1963; 39: 639-45.

5 Mackenzie A H, Scherbel A L. Connective tissue syndromes associated with carcinoma. Geriatrics 1963; 18: 745-53.

6 Zubler R M, Nydegger U, Perrin L H, et al. Circulating and intra-articular immune complexes in patients with rheumatoid arthritis. Correlation of $\mathrm{I}^{125} \mathrm{Clq}$ binding activity with clinical and biological features of the disease. J Clin Invest 1976; 57: 1308-19.

7 McCarty D J. (1979). Synovial fluid. In: McCarty D J, ed. Arthritis and Allied Conditions. 9th ed. Philadelphia: Lea and Febiger, 1979: 54.

8 Donelly B, Johnson P M. Detection of hypertrophic pulmonary osteoarthropathy by skeletal imaging with ${ }^{99 m}$ Tc-labelled diphosphonate. Radiology 1975; 114: 389-91.

9 Evans W K. Reversal of hypertrophic osteoarthropathy after chemotherapy for bronchogenic carcinoma. $J$ Rheumatol 1980; 7: 93-7.

10 Semple T, McCluskey B A. Generalised hypertrophic osteoarthropathy in association with bronchial carcinoma, a review based on 24 cases. Br Med J 1955; 1 : 754-9.

11 Vidal A F, Altman R D, Pardo V, Schultz D. Structural and immunologic changes of synovium of hypertrophic osteoarthropathy (HPO). Arthritis Rheum 1977; 20: 139. 